$\mathbb{P}$ periodica polytechnica

Mechanical Engineering

$53 / 1(2009) 19 \sqrt{26}$

doi: 10.3311/pp.me.2009-1.03

web: http://www.pp.bme.hu/me

(C) Periodica Polytechnica 2009

RESEARCH ARTICLE

\section{Energetic utilisation of biogases in IC engines}

\author{
Viktória Barbara Kovács / Attila Meggyes
}

Received 2010-01-18

\section{Abstract}

Due to increasing energy demand from the human population and in order to keep the development sustainable there is a major need to utilize alternative energy sources. The use of biogases as a source of renewable energy for combined heat and power generation could provide an effective and alternative way to fulfil remarkable part of this energy demand as a possible solution of decentralized power generation. Therefore the role of utilization of biogases grows rapidly in Europe and all around the world. As biogases have a high inert content, their heating value is low. The energetic utilization of these low heating value renewable gaseous fuels is not fully worked out yet because their combustion characteristics differ significantly from those of natural gases, and in this way they are not usable or their utilization in conventional devices is limited. At the Department of Energy Engineering of BME in cooperation with the Szolnok University College Technical and Agricultural Faculty investigation was made to determine the energetic usability of biogases. At Szolnok University experiments were made to increase the quantity and quality of biogas produced from different kind of basic materials and mixtures and at the Department of Energy Engineering of Budapest University of Technology and Economics the IC Engine utilization of biogases was investigated. The power, efficiency, consumption and exhaust emission were measured and in-cylinder pressure data acquisition was made to determine the pressure and heat release in the cylinder at various engine working conditions and $\mathrm{CO}_{2}$ contents.

\section{Keywords}

renewable · biogas $\cdot$ IC engine $\cdot$ power $\cdot$ efficiency $\cdot$ indication $\cdot$ heat release $\cdot$ exhaust emission

\section{Viktória Barbara Kovács}

Department of Energy Engineering, BME, H-1111 Budapest, 3 Múegyetem rkp, Hungary

e-mail: kovacsv@energia.bme.hu

\section{Attila Meggyes}

Department of Energy Engineering, BME, H-1111 Budapest, 3 Múegyetem rkp, Hungary

e-mail: meggyes@energia.bme.hu

\section{Introduction}

This paper is focusing on the investigation of combustion characteristics of biogases from the aspect of energetic utilization. The utilization of renewable alternative energy sources like liquid bio-fuels [4,5] or biogases will have a major role in mitigating the climate change while the increasing energy demand of humanity needs to be fulfilled and the sustainable development should be maintained. Renewable gaseous fuels like biogases utilized in IC engines in CHP units could provide an effective and alternative way to fulfil remarkable part of this energy demand because the total efficiency of a gas engine operated in cogeneration or trigeneration can be more than 90\% [2,12].

However several investigations were made to determine the combustion characteristics of biogases operating in various heat engines [6-8], the energetic utilization of biogases is not fully worked out yet because the combustion characteristics of biogases - due to their $\mathrm{CO}_{2}$ content -differ significantly from those of the conventional fuels like natural gas or LP gas, which are already used for power generation. So biogases are not usable or their utilization is limited in conventional furnaces.

Biogases contain a significant amount of $\mathrm{CO}_{2}$ beside methane depending on the production technology and it could be even up to $60-70 \%$ by volume. The $\mathrm{CO}_{2}$ content affects the combustion properties of biogases. $\mathrm{CO}_{2}$ is not combustible component. The constant pressure specific heat of $\mathrm{CO}_{2}$ is very high, moreover it dissociates into $\mathrm{CO}$ and $\mathrm{O}_{2}$ at higher temperature so it influences on slowing down the combustion process.

By increasing the $\mathrm{CO}_{2}$ content the adiabatic flame temperature and the flame velocity decrease which can cause burning instability and stretched combustion [1,2], and has negative effect on the engine operation (power, consumption) and exhaust emission [3]. However it works as an anti-knock agent too, so biogas with $30 \mathrm{~V} / \mathrm{V} \% \mathrm{CO}_{2}$ content is less prone to generate knock than pure methane.

Biogases with high $\mathrm{CO}_{2}$ content are common in Hungary. The utilization is more problematic if the composition of biogas is continuously changing by the time, which occurs in the case of sewage sludge gas and depony gas [13].

Therefore the energetic utilization of biogases in IC engines 
is problematic if their $\mathrm{CO}_{2}$ content is high. Therefore at the Department of Energy Engineering of BME in cooperation with the Szolnok University College Technical and Agricultural Faculty investigation were made to determine the energetic usability of biogases. At Szolnok University investigation was made to produce biogas with proper quantity and quality for IC engine operation. At the Department of Energy Engineering of BME measurements were made to determine the effect of the $\mathrm{CO}_{2}$ content of different biogases on the operation of IC Engine.

\section{Properties of biogases}

The $\mathrm{CO}_{2}$ content of biogases affects the combustion properties because $\mathrm{CO}_{2}$ is not combustible component; it has an influence on slowing down the combustion process. By increasing $\mathrm{CO}_{2}$ content the adiabatic flame temperature $[\mathrm{K}]$ and the laminar flame velocity $[\mathrm{cm} / \mathrm{s}]$ decrease (Fig. 1), the decrement of the laminar flame velocity is nearly linear, but the decrement of the adiabatic flame temperatures above $30 \mathrm{~V} / \mathrm{V} \% \mathrm{CO}_{2}$ content intensifies. In case of $40 \% \mathrm{CO}_{2}$ content the adiabatic flame temperature is only around $2100 \mathrm{~K}$ and the laminar flame velocity around $25 \mathrm{~cm} / \mathrm{s}$ which is only $60 \%$ of the laminar flame velocity of natural gas.

The values of these two combustion parameters are partly affected by the composition of the gaseous fuel and are influenced by the Lower Heating Value (LHV) of biogas, which is low. In case of $40 \% \mathrm{CO}_{2}$ content the LHV is only around $22 \mathrm{MJ} / \mathrm{m}^{3}$ (Fig.2).

Apart from the LHV, the Wobbe Number is a crucial parameter as far as combustion process of gaseous fuels is concerned. The Wobbe number shows the heat load of the combustion equipment, and can be calculated from:

$$
W o=\frac{H H V}{\sqrt{n}}
$$

where $H H V$ is the higher heating value $\left[\mathrm{MJ} / \mathrm{m}^{3}\right]$ of a fuel; $n$ is the relative density and can be calculated from the densities of fuel and air:

$$
n=\frac{\rho_{\text {fuel }}}{\rho_{\text {air }}}
$$

Even in case of gaseous fuels with equal HVV the Wobbe number can vary if the composition of the fuels is different because the relative density could be different. Considering that from the point of view of stable operation of the engine the variation of these two parameters should be kept in the range of $\pm 5 \%$ it is obvious that neither the LHV nor the Wobbe number can be kept in the required range in case of biogas operation, because a typical biogas contains at least 30-40V/V\% $\mathrm{CO}_{2}$ (Fig. 2) [10].

Fig. 2. also shows two dimensionless factors which were defined to determine the effect of the $\mathrm{CO}_{2}$ content of biogases on their combustion properties [11]. The LHV ratio $(\gamma)$ shows how much the LHV of natural gas (which was modelled with pure methane gas, because the natural gas "type D" that is provided in Hungary contains more than $98 \mathrm{~V} / \mathrm{V} \%$ methane) is higher when $\mathbf{u}[\mathbf{c m} / \mathbf{s}]$

- - o- - u u

$\cdots \Delta \cdot \cdots$ Tad

$\operatorname{Tad}[\mathrm{K}]$

40,0

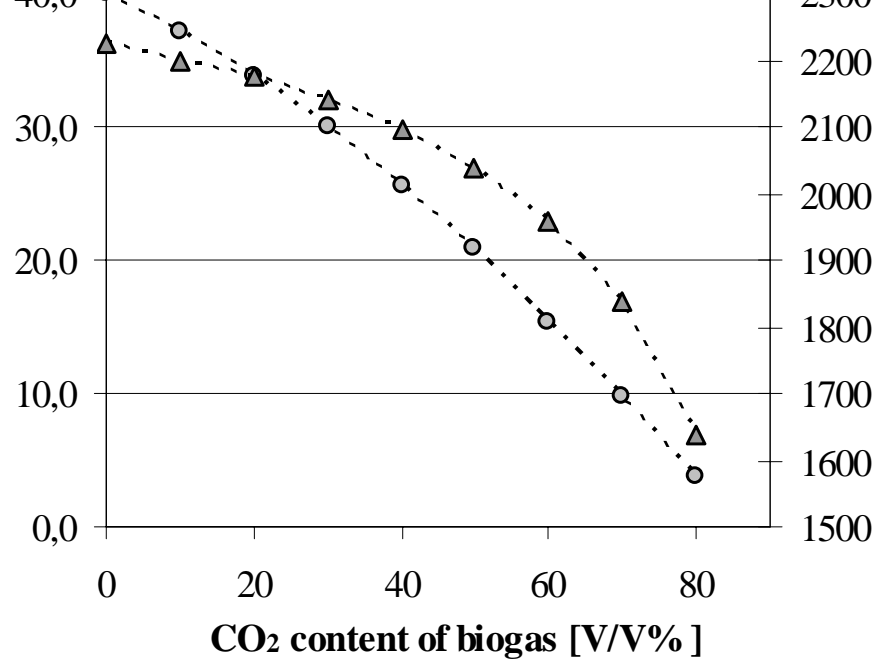

Fig. 1. Adiabatic flame temperature and laminar flame velocity against $\mathrm{CO}_{2}$ content at $(\lambda=1,273 \mathrm{~K}, 101325 \mathrm{~Pa})$

compared to biogas and is calculated from:

$$
\gamma=\frac{L H V_{N G}}{L H V_{\text {biogas }}}
$$

where $L H V_{N G}$ is the lower heating value of natural gas, and $L H V_{\text {biogas }}$ is the lower heating value of biogas both are calculated at $273 \mathrm{~K}$ and $101325 \mathrm{~Pa}$.

The next dimensionless factor, the theoretical fuel-air mixture volume ratio $(\varepsilon)$ shows how much biogas can be used if compared to natural gas to keep the excess air ratio of $1 \mathrm{~m}^{3}$ fuel - air mixture constant and is calculated from:

$$
\varepsilon=\frac{V_{0, N G}}{V_{0, \text { biogas }}}
$$

where $V_{0, N G}$ is the theoretical fuel-air mixture volume of natural gas and $V_{0, \text { biogas }}$ is the theoretical fuel-air mixture volume of biogas in case of stoichiometric mixture, and are calculated from:

$$
V_{0, i}=L_{0, i}+V_{f, i}
$$

where $L_{0, i}$ is the theoretical air requirement and $V_{f, i}$ is the volume of the fuel which is constant $1 \mathrm{~m}^{3}$ in case of stoichiometric mixtures and are calculated at $273 \mathrm{~K}$ and $101325 \mathrm{~Pa}$.

The value of these two factors $(\gamma, \varepsilon)$ depends on the $\mathrm{CO}_{2}$ content of the biogas. If the LHV ratio $(\gamma)$ and the theoretical fuelair mixture volume ratio $(\varepsilon)$ are equal at a given $\mathrm{CO}_{2}$ content, the LHV decrement of biogas caused by $\mathrm{CO}_{2}$ can be equalized by increasing fuel proportion of the fuel-air mixture.

Fig. 2 shows that the values of $\gamma$ and $\varepsilon$ are nearly the same until $40 \mathrm{~V} / \mathrm{V} \% \mathrm{CO}_{2}$ content but above it the decrement of the heating value is higher than the possible increment of the airfuel mixture volume flow so the effect of the decreasing heating value could not be equalized. This phenomenon was confirmed by the following measurements. 
According to the above mentioned properties of biogases it is necessary to investigate the impact of $\mathrm{CO}_{2}$ content of biogases on the operation parameters of IC engine, in view of power, efficiency, heat release, consumption and exhaust emission.

\section{Experimental set-up}

Measurements were made at the laboratory of the Department of Energy Engineering of BME in cooperation with the Szolnok University College Technical and Agricultural Faculty to determine the combustion characteristic of biogases on a BAG-30 gas engine unit which was modified for laboratory measurements (Fig. 3).

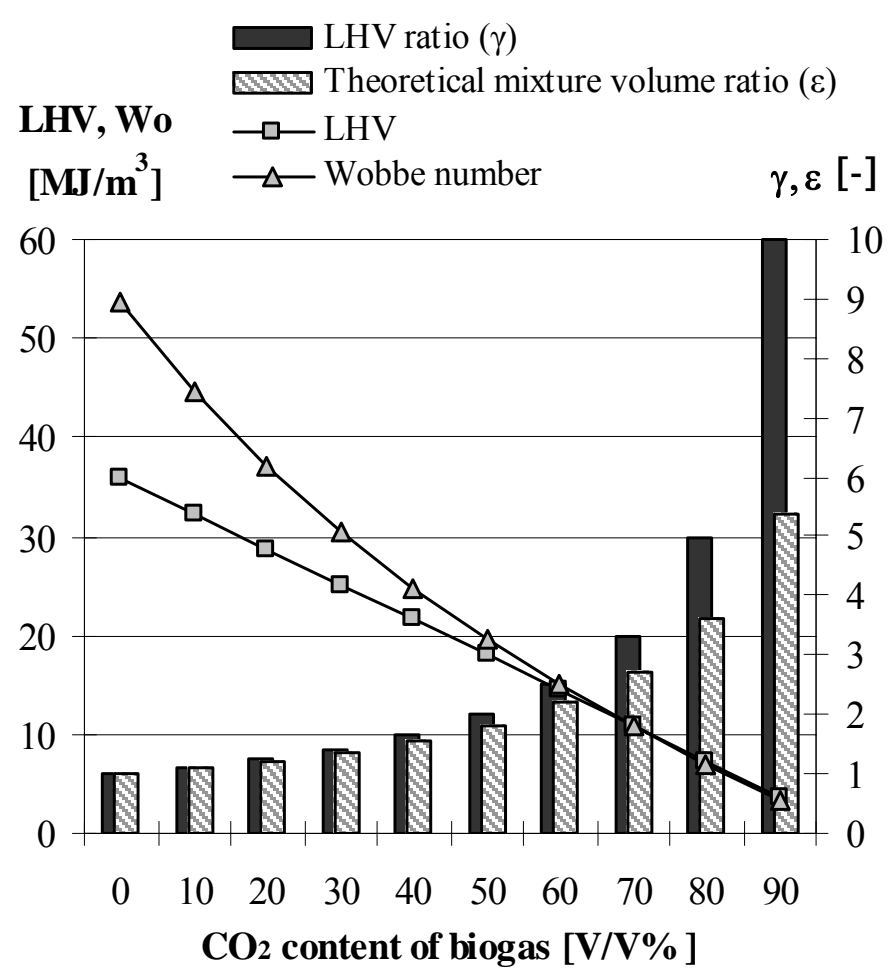

Fig. 2. LHV and Wobbe number; LHV- and theoretical fuel-air mixture volume ratios of different biogases against $\mathrm{CO}_{2}$ content, calculated at $273 \mathrm{~K}$ and $101325 \mathrm{~Pa}$

The biogases were modelled by $\mathrm{CO}_{2}$ - natural gas mixtures. The pure $\mathrm{CO}_{2}$ was tanked in a bundle and was mixed through a multistage pressure regulator to the natural gas and the mixture was aspirated by the engine. The homogenization of the mixture was prepared in a mixing unit. The composition of the mixture was controlled with a $\mathrm{CH}_{4}$ analyzer.

The control of the gas engine was made with the asynchronous generator of the engine. The constant speed was provided by a frequency inverter which was connected to the asynchronous generator. The electric power was measured with the frequency inverter. During the measurements intake pressure was kept at a constant value.

The evolved pressure was measured with a piezo pressure transducer in a Kistler 6517-A spark plug which was installed in the $1^{\text {st }}$ cylinder of the engine. Test series consist of 100 combustion cycles with sampling rate of 1024 per cycle and were averaged by statistical methods.
The gross heat release in the cylinder was calculated from the combustion pressure with a software which was developed at the Department of Energy Engineering [14].

The emissions of the gas engine were measured with a Horiba MEXA-8120F emission measuring system. The oxygen content of the exhaust gas which was needed for the determination of the excess air ratio $(\lambda)$ was measured by a SERVOMEX 570A oxygen analyzer. The measured data of the engine was recorded by electronic data collection system.

The reference measurements were made with natural gas (0V/V\% $\mathrm{CO}_{2}$ content). The impact of $\mathrm{CO}_{2}$ content of biogas was investigated on the engine performance. The measurements were made at 10-, 20-, 30-, 40- and 45V/V\% $\mathrm{CO}_{2}$ contents. At higher $\mathrm{CO}_{2}$ content the operation of the engine became unstable, so with higher than $45 \mathrm{~V} / \mathrm{V} \% \mathrm{CO}_{2}$ content measurements could not be made. Due to the comparability and reproducibility the measurements were made at constant spark timing, speed and boost pressure in case of several excess air ratios.

\section{Results}

The results of the measurements were analysed by both universities. At Szolnok the results were analysed from the point of view of biogas production. At the Department of Energy Engineering of BME the results were analysed with respect to combustion process and engine operation, as they are presented in this paper.

From the point of view of engine operation the in-cylinder peak pressure is very important parameter (Fig. 4), because it affects the power of the engine.

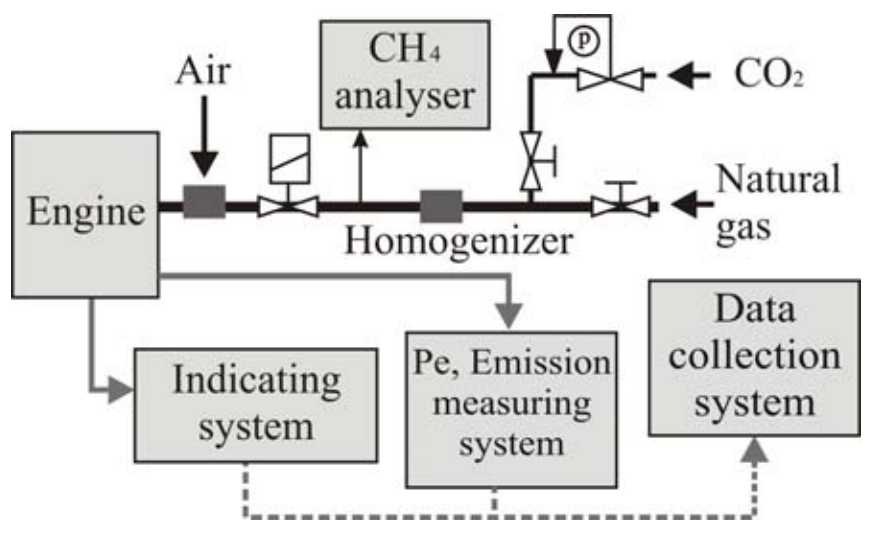

Fig. 3. Build-up of the measuring system

It is observed that not only the peak pressure decreases with increasing $\mathrm{CO}_{2}$ content of biogas but the operation range of the engine narrows as well. Namely in case of $40 \mathrm{~V} / \mathrm{V} \% \mathrm{CO}_{2}$ the operation range is only one third of the operation range of the reference measurement and it is shifted to leaner mixtures. In case of $40 \mathrm{~V} / \mathrm{V} \% \mathrm{CO}_{2}$ under $\lambda=1,33$ measurements could not be made, and in case of $45 \mathrm{~V} / \mathrm{V} \% \mathrm{CO}_{2}$ content the engine was able to operate only at one stable measuring point $(\lambda=1,56)$.

In order to compare the form of the cylinder pressures Fig. 5 shows the normalized measured pressures in the cylinder at con- 
stant air excess ratio $(\lambda=1,1)$ in case of $0-30 \mathrm{~V} / \mathrm{V} \% \mathrm{CO}_{2}$ content of biogas, but in case of higher $\mathrm{CO}_{2}$ contents this excess air ratio could not be kept. It is observable that the peak pressure not only decreases by increasing $\mathrm{CO}_{2}$ content, but it shifts further from the TDC which was adjusted to 360 degree.

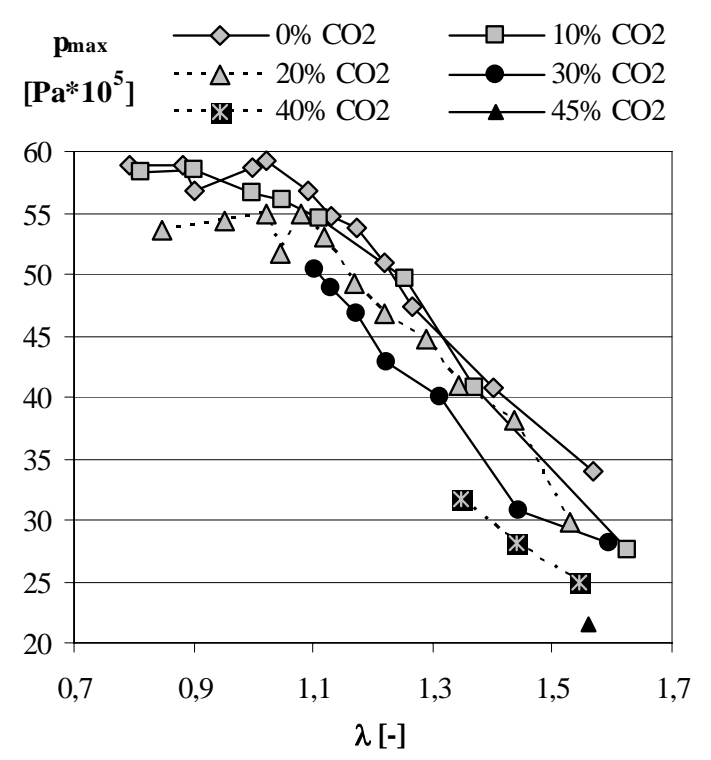

Fig. 4. In-cylinder combustion peak pressure against excess air ratio

Fig. 6 shows the normalized calculated heat release rate in the cylinder. It is observed that especially above $30 \mathrm{~V} / \mathrm{V} \% \mathrm{CO}_{2}$ content not only the maximum heat release rate decreases but stretched combustion takes place as well.

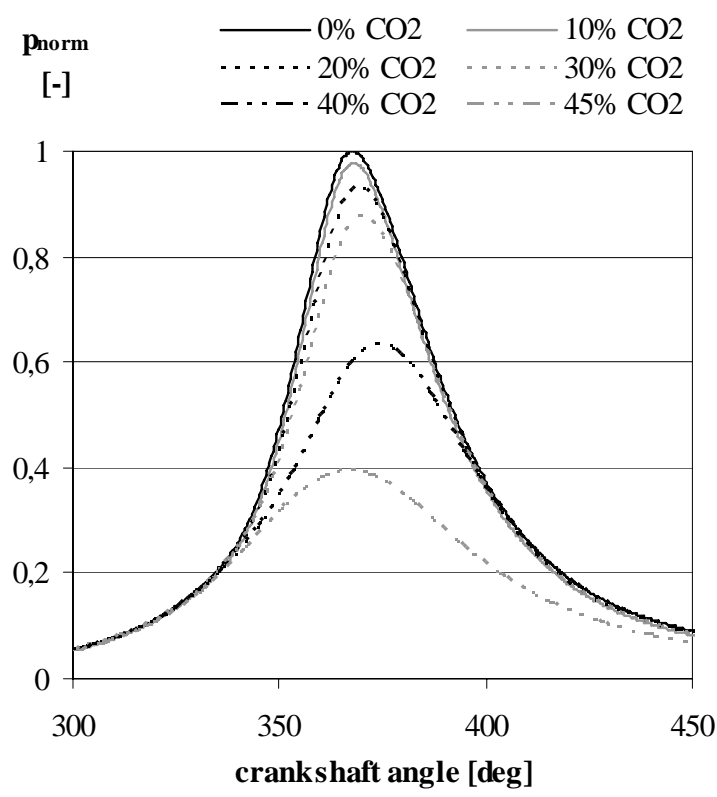

Fig. 5. Cylinder pressures at $\lambda=1,1$ in case of different $\mathrm{CO}_{2}$ contents of biogas

The influence of $\mathrm{CO}_{2}$ on the gross heat release is observed too. The heat release was calculated from the Energy Conservation by numerical integration (Fig. 7). It is noticed that the drop in the gross heat release is significant due to the lower LHV of biogases with $\mathrm{CO}_{2}$ content of $30 \%$ or higher significant.
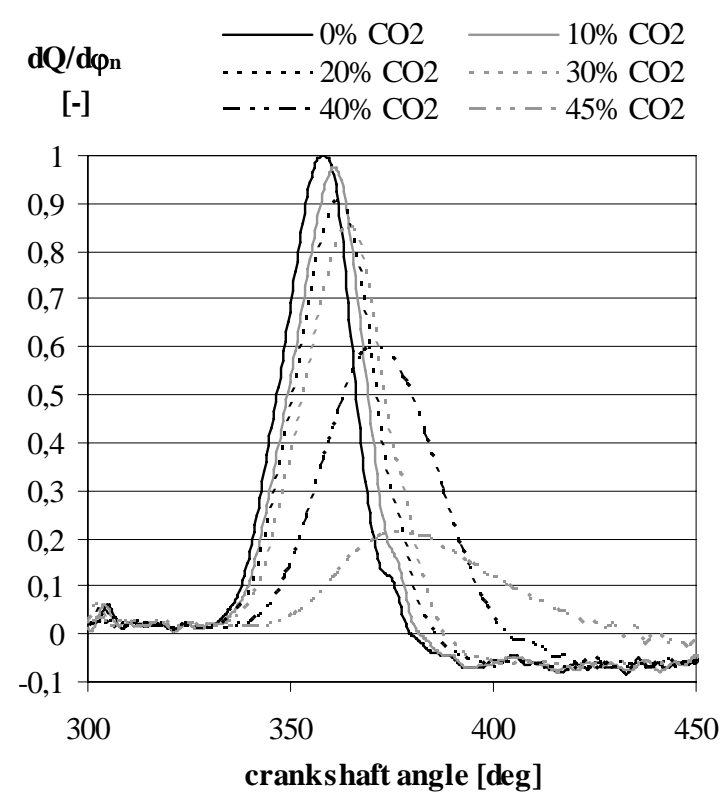

Fig. 6. Calculated heat release rate at $\lambda=1,1$

For better visualization the stretched combustion and negative effect of $\mathrm{CO}_{2}$ Fig. 8 shows the maximum heat release rate and the inherent crankshaft angles against the $\mathrm{CO}_{2}$ content of biogas.
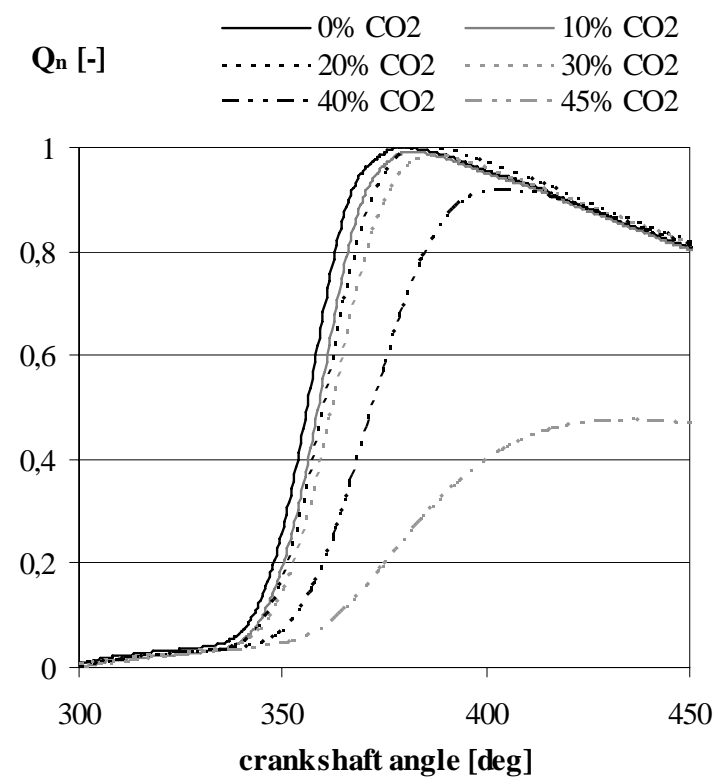

Fig. 7. Calculated heat release at $\lambda=1,1$

The curves are in good correlation with the calculated adiabatic flame temperature and laminar flame velocity (Fig. 1). As it was determined at the theoretical calculation above $30 \mathrm{~V} / \mathrm{V} \%$ $\mathrm{CO}_{2}$ content the negative effect of $\mathrm{CO}_{2}$ is stronger. Therefore the remarkable decrement of these combustion parameters involves the decrement of engine parameters too. In case of 40 $\mathrm{V} / \mathrm{V} \% \mathrm{CO}_{2}$ content the maximum heat release rate is only $60 \%$ of the maximum heat release rate of natural gas.

Stretched combustion is caused by the relevant decrement of laminar flame velocity and due to it remarkable part of the fuel burns after the TDC. It is observed that the shift from the TDC of the maximum heat release rate is non-linear, it intensifies by 
increasing $\mathrm{CO}_{2}$ content of biogas. Namely in case of $30 \% \mathrm{CO}_{2}$ content the shift is only $\sim 4$ degree but in case of $40 \% \mathrm{CO}_{2}$ content nearly 11 degree.

The stretched combustion is well observable at the exhaust gas temperatures too in case of lean fuel-air mixtures above $\lambda=1,3$ (Fig. 9). The exhaust gas temperature increases by increasing $\mathrm{CO}_{2}$ content of biogas since the combustion was not completed when the exhaust valve opened and after burning goes to the exhaust manifold.

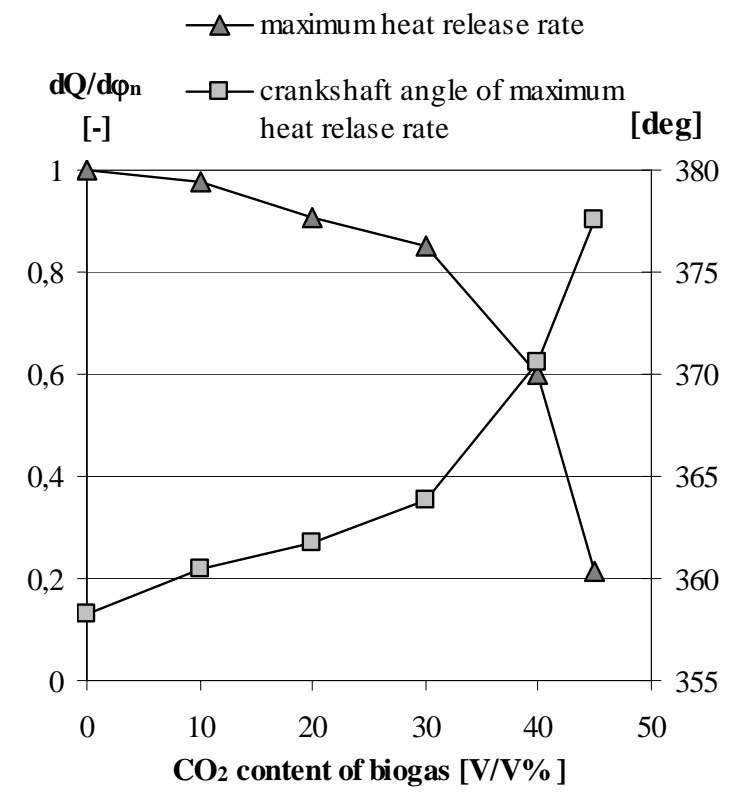

Fig. 8. Maximum heat release rate and its location against $\mathrm{CO}_{2}$ content of biogas at $\lambda=1,1$

The differences of the values of heat input $\left(\mathrm{Q}_{\text {in }}\right)$ are not relevant (Fig. 10). Due to decreasing LHV of biogases to keep the heat input constant at each operation condition the consumption needs to be increased by increasing $\mathrm{CO}_{2}$ content of biogas.

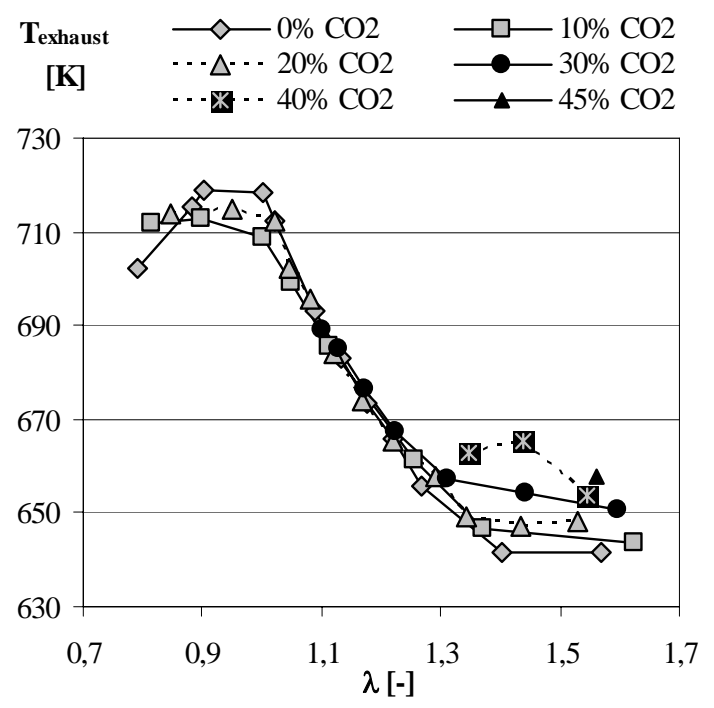

Fig. 9. Exhaust gas temperatures against $\mathrm{CO}_{2}$ content of biogas

Fig. 11 shows the measured biogas consumption. It is observed that not only the consumption increases with increasing
$\mathrm{CO}_{2}$ content of biogas but as it was expected above $40 \mathrm{~V} / \mathrm{V} \%$ $\mathrm{CO}_{2}$ content the LHV decrement could not be equalised by the increasing fuel proportion of the fuel-air mixture therefore the operation range narrowed and finally the engine was not able to operate when $\mathrm{CO}_{2}$ content was above $45 \mathrm{~V} / \mathrm{V} \%$.
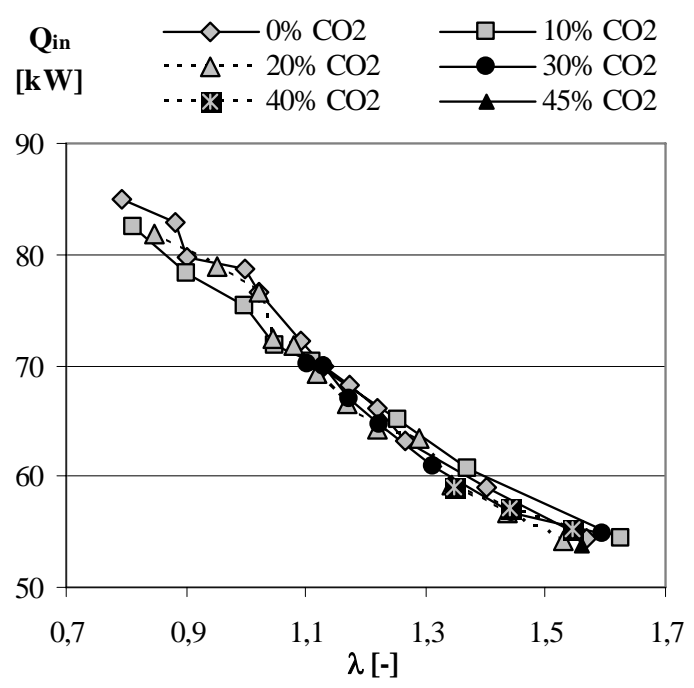

Fig. 10. Heat input against $\mathrm{CO}_{2}$ content of biogas

Fig. 12 shows that the decrement of the effective power is not really significant under $\lambda=1,2$ and $30 \mathrm{~V} / \mathrm{V} \% \mathrm{CO}_{2}$ content but above it intensifies. Even with increased consumption the effective power of the engine decreases because due to the high inert content incomplete combustion takes place [6]. In case of $\lambda=1,55$ and $45 \% \mathrm{~V} / \mathrm{V} \% \mathrm{CO}_{2}$ content the power drops from the reference value $11,5 \mathrm{KW}$ to $6,6 \mathrm{~kW}$ which is lower than the reference value by $42 \%$.

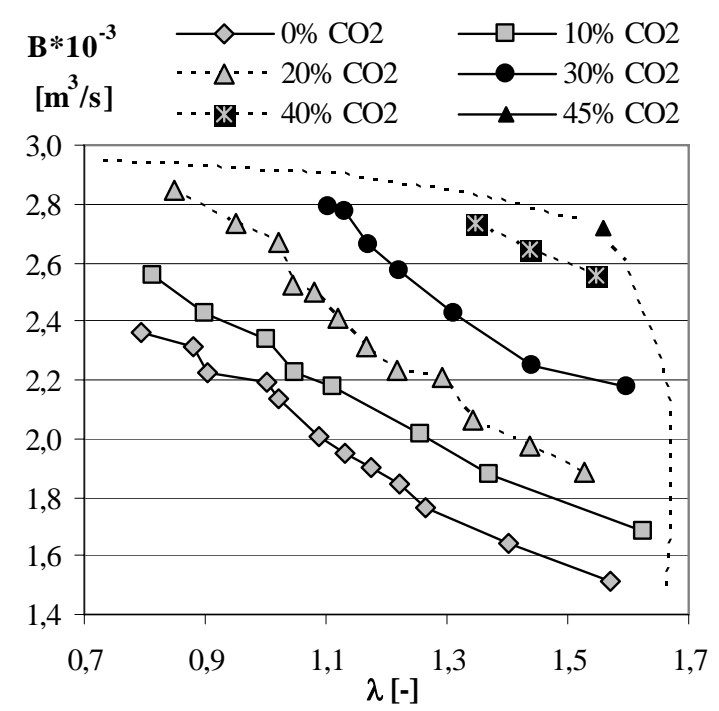

Fig. 11. Biogas consumption against $\mathrm{CO}_{2}$ content of biogas

The differences in useful heat $\left(\mathrm{Q}_{u s e f u l}\right)$ are not significant (Fig. 13). In case of over enriched mixtures the useful heat decreases as it was expected.

The profile of power and useful heat confirmed the measured exhaust temperatures, because the maximum temperatures are also around $\lambda=0.95$ and due to the air shortage they decrease 

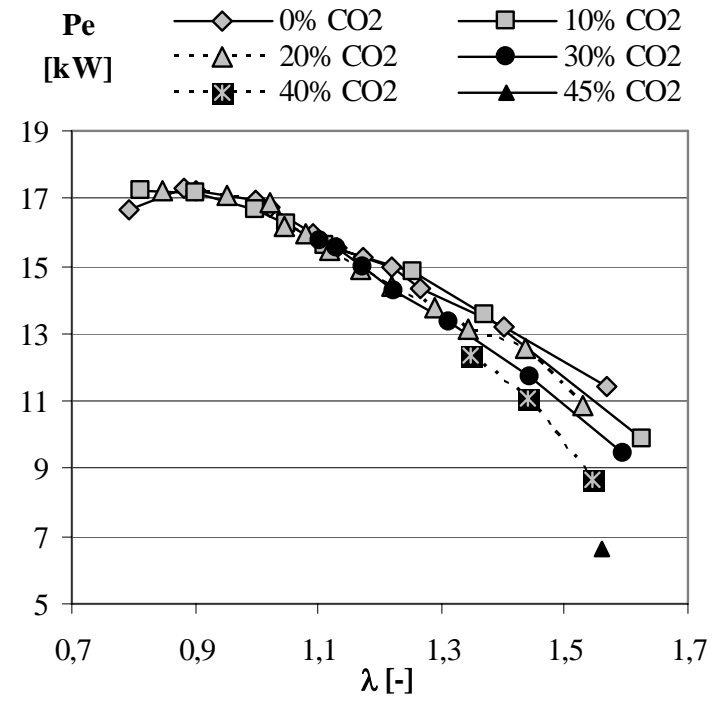

Fig. 12. Effective power against $\mathrm{CO}_{2}$ content of biogas

in case of richer and leaner mixtures too and even too much air cause incomplete combustion.

The efficiency curves evolved as it was expected [6]. Fig. 14 shows that the deviation of the values of thermal efficiency from each other is acceptable, relevant difference could not be experienced.
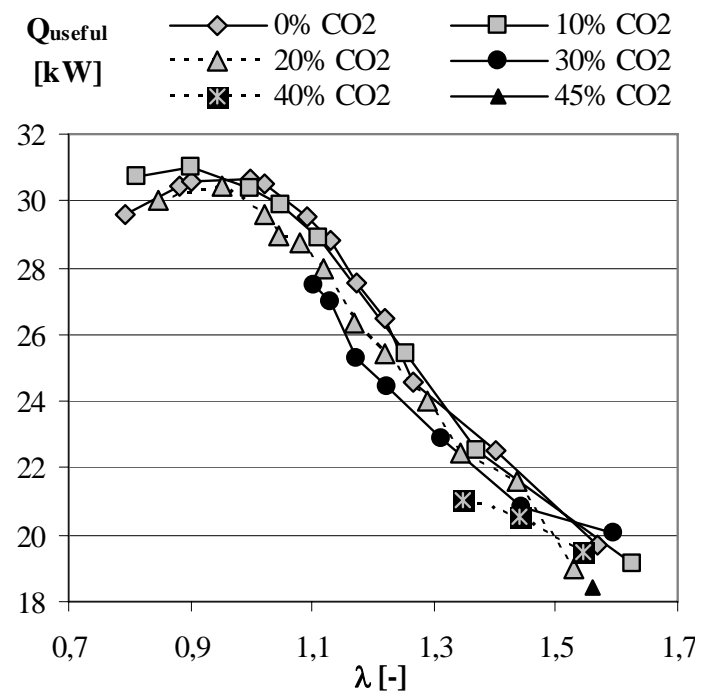

Fig. 13. Useful heat against $\mathrm{CO}_{2}$ content of biogas

The differences in the total efficiency under $\lambda=1,2$ and $30 \mathrm{~V} / \mathrm{V} \% \mathrm{CO}_{2}$ content are not relevant, but above it due to the relevant effective power drop the decrement of the total efficiency is relevant too (Fig. 15.

The results of the exhaust gas emission measurements turned out as expected [12].

The emission of $\mathrm{CO}_{2}$ increases with increasing $\mathrm{CO}_{2}$ content of biogas, due to the higher $\mathrm{CO}_{2}$ proportion of the fuel mixture (Fig. 16). The $\mathrm{CO}_{2}$ emissions are in good correspondence with the power, useful heat and temperature. The maximum $\mathrm{CO}_{2}$ emissions are around $\lambda=0.95$ where the temperature, useful heat and power maximums lay. In case of richer and leaner mixtures the $\mathrm{CO}_{2}$ emission decreases.
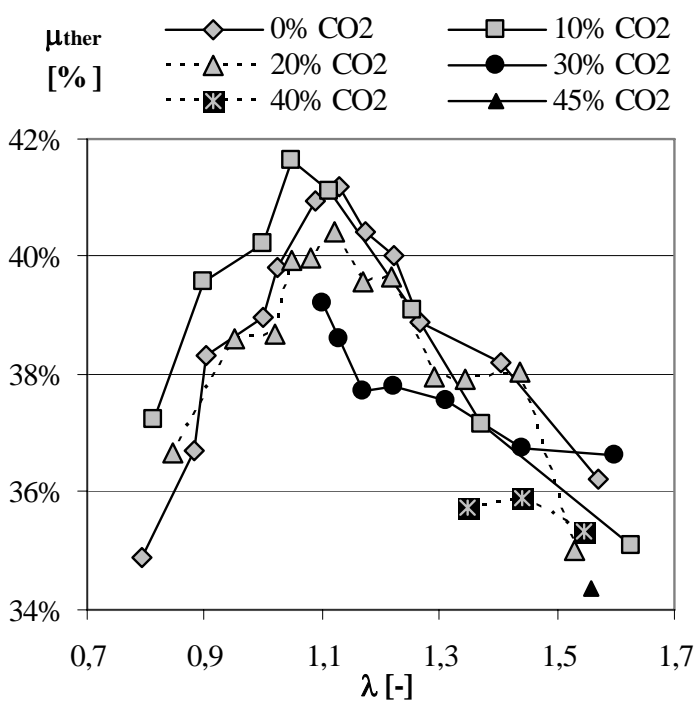

Fig. 14. Thermal efficiency against $\mathrm{CO}_{2}$ content of biogas
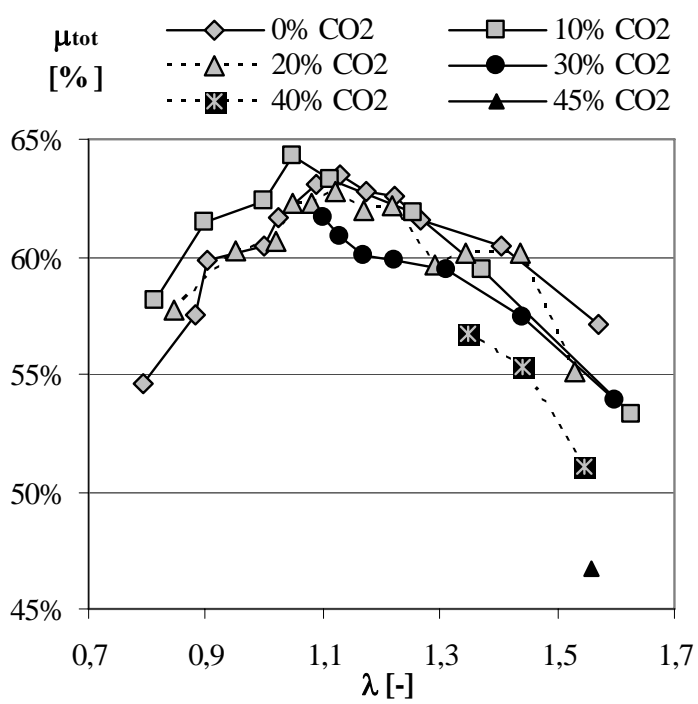

Fig. 15. Total efficiency against $\mathrm{CO}_{2}$ content of biogas

The NO emissions were as expected [9]. The reduction of the NO emissions is relevant since the NO formation mainly depends on the peak combustion temperature and increasing $\mathrm{CO}_{2}$ content has negative effect on the flame temperature. The shape of the curves of NO emission is acceptable. The NO maximum are around $\lambda=1.1$ and decreases both in case of lower and higher excess air ratios (Fig. 17).

The negative effect of $\mathrm{CO}_{2}$ on the products of incomplete combustion is not as significant as it was in the case of NO emission. Although the flame temperature decreases and stretched combustion takes place the products of incomplete combustion are not increasing in the range of perfect combustion, because the combustion could finish in the exhaust pipe before the sampling point.

Therefore the change in the THC emissions is not relevant. The shape of the curves of the THC emissions is acceptable. The minimum of THC emissions is around $\lambda=1.1$ and they increase both in case of lower and higher excess air ratios as incomplete combustion takes place. That is in good correspondence with 

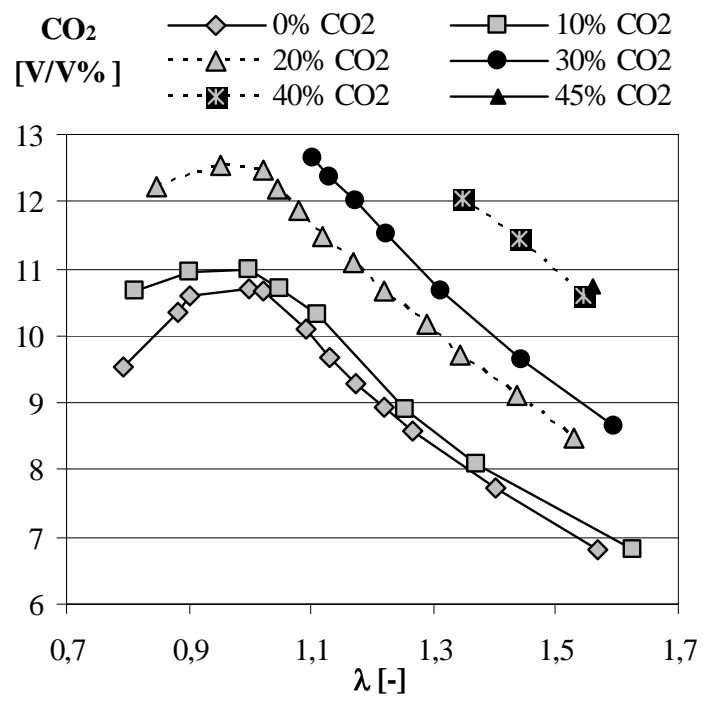

Fig. 16. $\mathrm{CO}_{2}$ emissions against $\mathrm{CO}_{2}$ content of biogas

the NO emissions (Fig. 18).

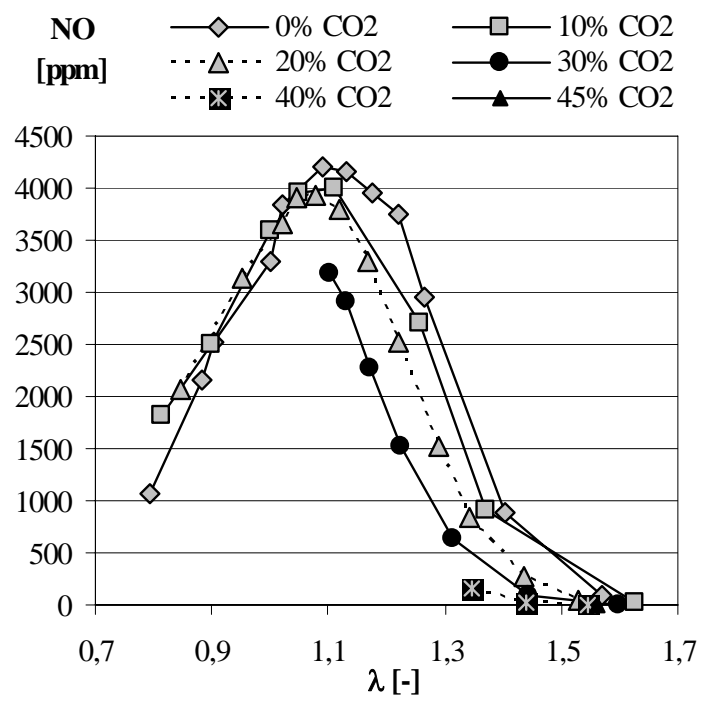

Fig. 17. $\mathrm{NO}$ emissions against $\mathrm{CO}_{2}$ content of biogas

Alike in the case of THC emission the change of $\mathrm{CO}$ emissions is not significant either. The shape of the curves of $\mathrm{CO}$ emissions formed also as they were expected. In case of lean mixtures the $\mathrm{CO}$ emission is around $500 \mathrm{ppm}$, but for $\lambda$ above 1,5 it slightly increases by the $\mathrm{CO}_{2}$ content of the biogas and in case of enriching the fuel-air mixtures it increases considerably due to the absence of oxidizer (air) caused incomplete combustion (Fig. 19).

\section{Conclusions}

From the theoretical calculations and measurements of biogases it can be concluded that the energetic utilization of biogases in IC engines is limited because the $\mathrm{CO}_{2}$ content delays the combustion, and above a given $\mathrm{CO}_{2}$ content the combustion could not take place. Accordingly the operation range of the engine narrows with increasing $\mathrm{CO}_{2}$ content of biogas and at the given operation conditions above $45 \mathrm{~V} / \mathrm{V} \% \mathrm{CO}_{2}$ content the
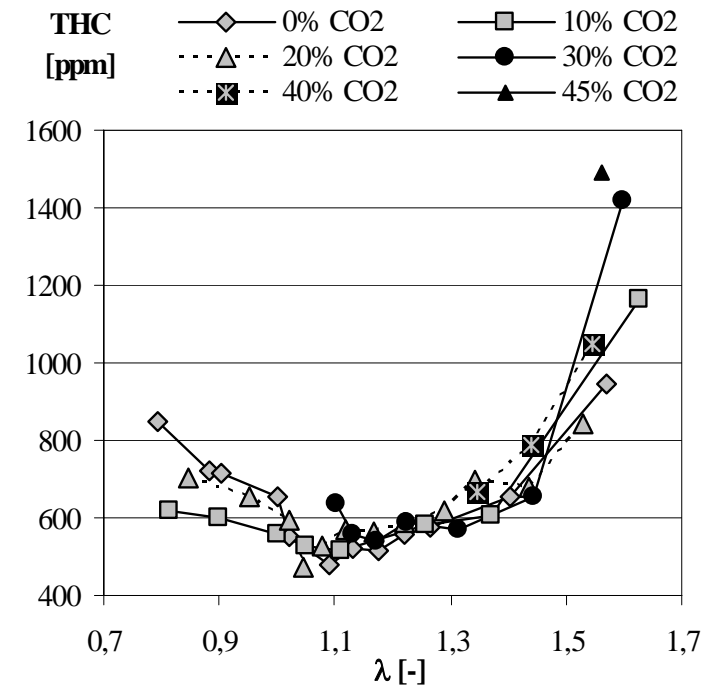

Fig. 18. THC emissions against $\mathrm{CO}_{2}$ content of biogas
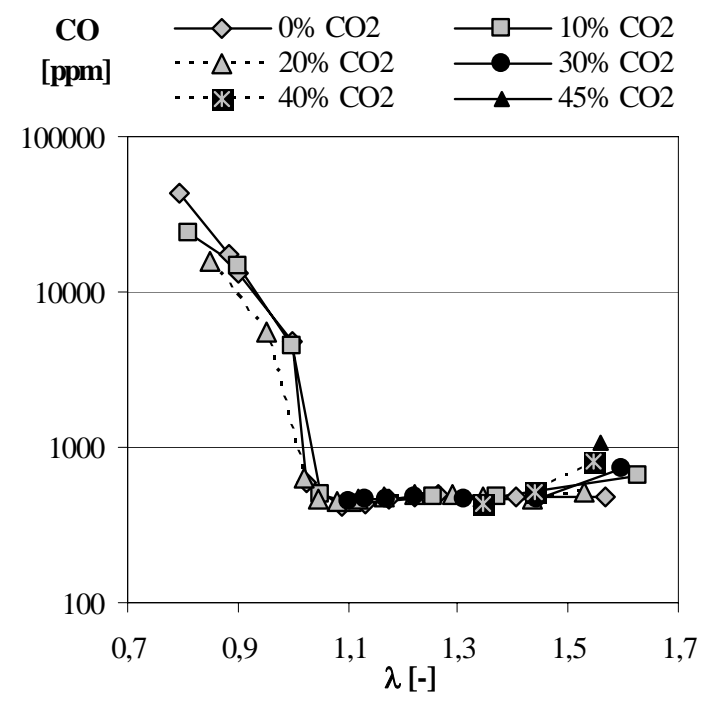

Fig. 19. $\mathrm{CO}$ emissions against $\mathrm{CO}_{2}$ content of biogas

engine was unable to run on fuel with such high inert content.

Due to the decreasing LHV by the increasing $\mathrm{CO}_{2}$ content of biogas the consumption increases and so does the $\mathrm{CO}_{2}$ emission. The negative effect of $\mathrm{CO}_{2}$ on the combustion is proved on the maximum pressure, heat release, effective power, total efficiency and on $\mathrm{NO}$ emission as well because they all decrease mainly above $30 \mathrm{~V} / \mathrm{V} \% \mathrm{CO}_{2}$ content. This was in good correspondence with the theoretical calculations.

The stretched combustion caused by the increasing $\mathrm{CO}_{2}$ content is well detectable on the heat release rate (above $30 \mathrm{~V} / \mathrm{V} \% \mathrm{CO}_{2}$ ) and exhaust temperature diagrams (above $\lambda=1,3)$.

In case of the other measured engine parameters significant change could not be detected with the increasing $\mathrm{CO}_{2}$ content of biogas. Increase in the products of incomplete combustion could not be detected; although stretched combustion took place the unburned fuel fraction was able to burn completely in the exhaust pipe.

According to the results above $30 \mathrm{~V} / \mathrm{V} \% \mathrm{CO}_{2}$ content the IC 
engine needs to be adjusted to the biogas to avoid considerable losses.

\section{References}

1 Bereczky Á, Gróf Gy, Kovács V B, Könczöl S, Lezsovits F, Meggyes A, Penninger A, K. Sztankó, Utilization of Gas Mixtures Having High Inert Content Generated from Biomass in Gas-Engine and in Gasturbine, Deutscher Flammentag - Verbrennung und Feuerungen Braunschweig (2005), 267-272.

2 Meggyes A, Bereczky Á, Energetic analysis of combined gas engine systems, Energetika (2007), 18-22. (in Hungarian).

3 Kovács V B, Meggyes A, Bereczky Á, Papp J, Investigation of Exhaust Emission of Biogas Oprated IC engine (2008), 218-221. különszám.

4 Laza T, Bereczky Á, Determination of the Evaporation Constant in Case of Pure and with Alcohol Mixed Rape Seed Oil, 16th International Conference in Mechanical Engineering, 2008, pp. 232-237.

5 Bereczky Á, Utilisation of biofuels in internal combustion engines, Proceedings of Conference on Heat Engines and Environmental Protection, 2008, pp. 43-47.

6 Porpatham E, Ramesh A, Nagalingam B, Investigation on the effect of concentration of methane in biogas when used as a fuel for a spark ignition engine, Fuel 87 (2008), 1651-1659, DOI 10.1016/j.fuel.2007.08.014.

7 Henham A, Makkar M K, Combustion of simulated biogas in a dual-fuel diesel engine, Energy Conversion and Management 39 (1998), 2001-2009.

8 Huang J D, Crookes $\mathbf{R} \mathbf{J}$, Assessment of simulated biogas as a fuel for the spark ignition engine, Fuel 77 (1998), 1793-1801.

9 Crookes $\mathbf{R} \mathbf{J}$, Comparative bio-fuel performance in internal combustion engines, Biomass and Bioenergy 30 (May 2006), 461-468, DOI 10.1016/j.biombioe.2005.11.022.

10 Kovács V B, Theoretical and Experimental Investigation of Biogases, Proceedings of International Youth Conference on Energetics, Budapest, 4 June, 2009, pp. 1-5.

11 Kovács V B, Meggyes A, Bereczky Á, Investigation of utilization of pirolysis gases in IC engine, Proceeding of Sixth Conference on Mechanical Engineering, 2008, pp. 153-157.

12 Nagy V, Meggyes A, Utilization of biogas in gas engines, $8^{\text {th }}$ International Conference on Heat Engines and Environmental Protection, Balatonfüred, May 2007. Proceedings.

13 Ősz J, Environment Friendly Utilisation of Lean Gases. NKFP Projekt Nr. 3/018/2001.

14 Lukács K, Development of a Dual Fuels Diesel Engine System for Power Generation, 2007. Diploma, Dep. Energy Eng., BME. 